\title{
PENGKAJIAN STRES PADA PENYANDANG DIABETES MELLITUS
}

\author{
Ria Afnenda Naibaho ${ }^{1}$, Niken Safitri DyanKusumaningrum ${ }^{2 *}$ \\ ${ }^{1}$ Program Studi Ilmu Keperawatan, Departemen Keperawatan, Fakultas Kedokteran, Universitas Diponegoro, \\ Jl. Prof. Soedarto, Tembalang, Kec. Tembalang, Kota Semarang, Jawa Tengah, Indonesia 50275 \\ ${ }^{2}$ Divisi Keperawatan Dewasa, Departemen Ilmu Keperawatan, FakultasKedokteran, Universitas Diponegoro, \\ Diponegoro, Jl. Prof. Soedarto, Tembalang, Kec. Tembalang, Kota Semarang, Jawa Tengah, Indonesia 50275 \\ *niken.safitridk@fk.undip.ac.id
}

\begin{abstract}
ABSTRAK
Stres dapat dialami oleh penyandang Diabetes Mellitus atau DM karena harus menjalankan perubahan pola hidup seperti pengaturan pola makan, kontrol gula darah, mengkonsumsi obatobatan, dan memperbanyak aktivitas yang bertujuan agar tidak terjadi peningkatan gula darah. Penelitian ini bertujuan untuk mengidentifikasi tingkat stres yang dialami oleh penyandang DM. Penelitian ini merupakan penelitian kuantitatif dengan pendekatan cross sectional dan menggunakan instrumen penelitian berupa kuesioner Depression Anxiety Stres Scale (DASS). Pengambilan sampel dilaksanakan selama bulan Mei 2018 menggunakan teknik consecutive sampling pada pasien di Rowosari, Semarang. Sebanyak 112 responden telah berpartisipasi dalam penelitian ini. Analisis data dilakukan secara univariat yang memaparkan frekuensi dan persentase. Hasil penelitian ini menunjukkan bahwa mayoritas responden yang berpartisipasi adalah perempuan $(77,7 \%)$ dan mengalami komplikasi $(82,1 \%)$. Temuan lainnya menunjukkan bahwa lebih banyak penyandang DM yang mengalami stres sedang $(32,1 \%)$ daripada stres normal, ringan, berat atau sangat berat. Penyandang DM yang memiliki tingkat stres sedang memiliki ciri-ciri mudah marah, mudah sensitif, sulit beristirahat, merasa lelah karena cemas, tidak sabar, gelisah, dan tidak dapat memaklumi hal yang dapat menganggu. Secara umum, kebanyakan penyandang DM sering kali menghabiskan banyak energi untuk merasa cemas dan juga sulit untuk beristirahat.
\end{abstract}

Kata kunci: diabetes mellitus, glukosa darah, kadar glukosa darah, stres

\section{ASSESSMENT OF STRESS IN PATIENTS WITH DIABETES MELLITUS}

\begin{abstract}
Stress can be experienced by patients with Diabetes Mellitus or DM because they have to run lifestyle changes such as diet, blood sugar control, drugs consumption, and reproduce activities aimed at not increasing blood sugar. The study aimed to determine level of stress in diabetes patients in patients with DM. This research was a quantitative research with cross sectional approach and using Depression Anxiety Stress Scale (DASS) questionnaire. Consecutive sampling technique was used to gather the data from respondents in Rowosari Semarang in May 2018. One hundred and twelve patients full-filed the questionnaire. Data analysis was carried out univariately which explained the frequency and percentage. The majority of respondents were women (77.7\%) and had complication of DM $(82.1 \%)$. Findings also revealed that more of diabetes patients have experienced moderate stress (32.1\%) than normal, mild, severe, or very severe. Patients with diabetes who have moderate levels of stress have characteristics of easy irritated, sensitive, difficult to rest, displeasure, anxious, and cannot understand things easily. Generally speaking, more diabetes patients consume more energy for worry something easily irritated and difficult to rest.
\end{abstract}

Keywords: diabetes mellitus, blood glucose, blood glucose level, stress

\section{PENDAHULUAN}

Diabetes Mellitus (DM) adalah salah satu penyakit gangguan metabolisme yang berlangsung kronis dengan karakteristik hiperglikemia (Perkumpulan Endokrinologi Indonesia (Perkeni), 2015). Penyakit DM juga merupakan suatu penyakit kronis yang mempunyai dampak negatif terhadap fisik maupun psikologis penderita (Utami, Jamaluddin, \& Khsanah, 2016; Utamie Puji Lestari, Kanbara, Setyawan, \& Taniguchi, 2008). Banyak penyandang DM tidak 
menyadari bahwa mereka telah mengidap diabetes. Penyandang DM biasanya baru menyadari setelah mereka mengalami berbagai komplikasi seperti retinopati diabetik, nefropati diabetik, neuropati diabetik, dan ulkus kaki diabetik (Zainuddin, Utomo, \& Herlina, 2015).

Sebuah penelitian mengatakan bahwa penyandang DM yang telah terdiagnosa mengalami penyakit DM harus menjalankan perubahan pola hidup seperti pengaturan pola makan atau diet, kontrol gula darah, mengkonsumsi obat-obatan, dan memperbanyak aktivitas yang bertujuan agar tidak terjadi peningkatan gula darah. Hal ini dapat mengakibatkan penyandang DM menunjukkan reaksi psikologis yang negatif seperti marah, stres dan depresi (Septian Adi Nugroho \& Purwanti, 2013). Selain itu, tidak jarang penderita menjadi semakin stres jika muncul komplikasi penyakit DM (Yan, Marisdayana, \& Irma, 2017).

Stres merupakan reaksi tubuh terhadap situasi yang menimbulkan tekanan, perubahan, dan ketengangan emosi (Renabir \& Reetu, 2011). Stres dua kali lebih mudah menyerang penyandang diabetes dibandingkan orang yang tidak mengidap diabetes (Utami et al., 2016). Stres yang dialami oleh penyandang DM dapat berdampak pada gangguan pengontrolan glukosa. Pada keadaan stres akan terjadi peningkatan produksi berlebih pada kortisol yaitu hormon yang dapat melawan efek insulin dan menyebabkan kadar glukosa darah tinggi (Pratiwi, Amatiria, \& Yamin, 2014; Strandberg, Graue, Wentzel-Larsen, Peyrot, \& Rokne, 2014). Stres yang tinggi dapat memicu peningkatan kadar glukosa darah dalam tubuh sehingga semakin tinggi stres yang dialami oleh penyandang DM maka DM yang diderita juga semakin bertambah buruk (Derek, Rottie, \& Kallo, 2017).

Salah satu penelitian tentang stres dan kadar glukosa darah menunjukkan bahwa terdapat hubungan tingkat stres dengan glukosa pada penyandang DM (Lutfi Wahyuni, 2015). Stres dan DM mempunyai hubungan yang sangat erat terutama pada penyandang DM yang tinggal di perkotaan. Hal ini dapat disebabkan oleh tekanan kehidupan, gaya hidup yang tidak sehat, perkembangan teknologi yang semakin meningkat, dan penyakit lain yang sedang diderita. Kondisi ini pada akhirnya menyebabkan penurunan kondisi kesehatan seseorang sehingga dapat memicu terjadinya stres (Septian Adi Nugroho \& Purwanti, 2013). Stres fisiologik yang dialami penyandang DM dapat berupa gangguan pengontrolan glukosa, luka yang lama sembuh, mudah haus, mudah lapar, mengeluh lelah, dan mengantuk (Pratiwi et al., 2014). Stres mental pada penyandang DM dapat berupa berkurangnya peran dalam rumah tangga, hilangnya pekerjaan, dan pendapatan yang menurun. Selain itu, secara sosial seorang penyandang DM dengan luka diabetik juga akan dikucilkan oleh orang lain karena luka yang tampak kotor dan bau yang ditimbulkan. Sedangkan stres emosional pada penyandang DM seperti sikap menyangkal, obsesi, marah, takut, dan frustasi (Utami et al., 2016; Yan et al., 2017).

Pengkajian mendalam terkait stres yang dialami penyandang DM belum banyak diteliti secara komprehensif. Oleh karena itu, penelitian ini penting dilakukan agar nantinya masyarakat dan tenaga kesehatan dapat mengenali bentuk maupun manifestasi stres yang dialami oleh penyandang DM. Penelitian ini bertujuan untuk mengidentifikasi tingkat stres yang dialami penyandang DM di Wilayah Kerja Puskesmas Rowosari Semarang melalui pendekatan penelitian deskriptif.

\section{METODE}

Penelitian ini merupakan jenis penelitian kuantitatif deskriptif dengan pendekatan cross sectional. Teknik pengambilan sampel secara consecutive sampling dilakukan pada penyandang DM yang terdaftar pada rekam medis puskesmas di bulan Mei 2018. Jumlah sampel sebesar 112 penyandang DM di Wilayah Kerja Puskesmas Rowosari Semarang. Instrumen yang digunakan adalah Depression Anxiety Stress Scale (DASS) versi bahasa Indonesia dengan nilai validitas r hitung 0,35-0,75 dan nilai reliabilitas 0,88 . Analisis data secara univariat dilakukan untuk mengintepretasi hasil yang diperoled dan dipaparkan dalam bentuk distribusi frekuensi dan persentase. Penelitian ini telah disetujui oleh Komisi Etik Penelitian Kesehatan Fakultas Kedokteran Universitas 
Diponegoro dengan nomor 296/EC/FKRSDK/V/2018.

\section{HASIL}

Hasil penelitian menunjukkan bahwa mayoritas responden yang berpartisipasi dalam penelitian ini adalah responden yang berusia dewasa tengah $(66,1 \%)$ dan telah menderita DM selama 1-5 tahun $(64,3 \%)$. Karakteristik sosio-demografi responden secara detail, disampaikan pada tabel 1 .

Tabel 1.

Karakteristik sosio-demografi penyandang DM $(\mathrm{n}=112)$

\begin{tabular}{|c|c|c|}
\hline Karakteristik & $\mathrm{f}$ & $\%$ \\
\hline \multicolumn{3}{|l|}{ Jenis Kelamin } \\
\hline Laki-laki & 25 & 22,3 \\
\hline Perempuan & 87 & 77,7 \\
\hline \multicolumn{3}{|l|}{ Usia } \\
\hline 18-40 tahun & 2 & 1,8 \\
\hline $41-<60$ tahun & 74 & 66,1 \\
\hline 260 tahun & 36 & 32,1 \\
\hline \multicolumn{3}{|l|}{ Pendidikan } \\
\hline Tidak sekolah & 55 & 49,1 \\
\hline SD & 33 & 29,5 \\
\hline SMP & 8 & 7,1 \\
\hline SMA & 9 & 8,0 \\
\hline Perguruan tinggi & 7 & 6,3 \\
\hline \multicolumn{3}{|l|}{ Pekerjaan } \\
\hline Tidak bekerja & 36 & 32,1 \\
\hline Wiraswasta & 16 & 14,3 \\
\hline PNS & 7 & 6,3 \\
\hline Petani & 18 & 16,1 \\
\hline Pegawai Swasta & 20 & 17,9 \\
\hline Lain-lainnya & 15 & 13,4 \\
\hline \multicolumn{3}{|l|}{ Lama menderita } \\
\hline$<1$ tahun & 4 & 3,6 \\
\hline $1-5$ tahun & 72 & 64,3 \\
\hline$>5$ tahun & 36 & 32,1 \\
\hline \multicolumn{3}{|l|}{ Riwayat penyakit keluarga } \\
\hline Ya & 39 & 34,8 \\
\hline Tidak & 73 & 65,2 \\
\hline \multicolumn{3}{|l|}{ Riwayat penyakit penyerta } \\
\hline $\mathrm{Ya}$ & 58 & 58,2 \\
\hline Tidak & 54 & 51,8 \\
\hline \multicolumn{3}{|l|}{ Komplikasi } \\
\hline Ya & 92 & 82,1 \\
\hline Tidak & 20 & 17,9 \\
\hline
\end{tabular}

Tabel 2.

Tingkat stres penyandang DM $(\mathrm{n}=112)$

\begin{tabular}{|c|c|c|}
\hline Tingkat Stres & $\mathrm{f}$ & $\%$ \\
\hline Stres Normal & 16 & 14,3 \\
\hline Stres Ringan & 34 & 30,4 \\
\hline Stres Sedang & 36 & 32,1 \\
\hline Stres Berat & 20 & 17,9 \\
\hline Stres Sangat Berat & 6 & 5,4 \\
\hline
\end{tabular}

Tabel 2 menunjukkan bahwa lebih banyak penyandang DM yang mengalami stres 
sedang (36 responden, 32,1\%), dibandingkan penyandang DM yang mengalami stres normal, ringan, berat, dan sangat berat.

\section{PEMBAHASAN}

Berbagai kondisi yang dialami oleh penyandang DM sering kali menyebabkan stres, yang pada akhirnya dapat mempengaruhi perkembangan penyakitnya. Studi mengenai diabetes dan stres telah menunjukkan terdapat beberapa mekanisme yang dapat dipertimbangkan terkait dengan munculnya stres yang dapat mempengaruhi DM (Hermanns, Kulzer, Ehrmann, BergisJurgan, \& Haak, 2013; Kelly \& Ismail, 2015; Lloyd, Smith, \& Weinger, 2005; Zhou et al., 2017). Fenomena tentang stres pada penyandang DM cenderung diidentifikasi sebagai hal yang baru dibandingkan dengan gangguan psikologis lain yang pernah ditemukan (Rariden, 2019).

Hasil penelitian menunjukkan bahwa mayoritas penyandang DM mengalami stres sedang. Hasil penelitian ini memiliki persamaan dengan penelitian yang dilakukan oleh Wahyuni yang menunjukkan bahwa stres penyandang DM dalam kategori stres sedang (Lutfi Wahyuni, 2015). Stres sedang biasanya berlangsung beberapa jam sampai beberapa hari. Penyandang DM yang memiliki tingkat stres sedang memiliki ciriciri mudah marah, mudah sensitif, sulit beristirahat, merasa lelah karena cemas, tidak sabaran, gelisah, dan tidak dapat memaklumi hal yang dapat menganggu. Hal tersebut sesuai dengan jawaban penyandang DM pada lembar kuesioner yaitu menjadi marah karena hal-hal sepele, mudah tersinggung, sulit untuk beristirahat, banyak menghabiskan energi karena cemas, merasa tidak sabaran, mudah gelisah, dan tidak dapat memaklumi hal apapun yang dapat menghalangi dalam menyelesaikan masalah. Penyandang DM yang mengalami stres sedang menunjukkan respon emosi (Bruce, 2013; Setyorini, 2017). Semakin tinggi stres yang dialami penyandang DM maka semakin banyak pula permasalahan emosional yang dialami oleh penyandang DM. Hal ini berhubungan dengan melemahnya kepatuhan penyandang DM diabetes dalam mematuhi penatalaksanaan pengobatan DM, sehingga glukosa akan cenderung meningkat yang akan berdampak pada penurunan kualitas hidup penyandang DM (Septian Adi Nugroho \& Purwanti, 2013).

Hasil penelitian juga menunjukkan terdapat penyandang DM yang mengalami stres ringan. Pada keadaan stres ringan penyandang DM biasanya menjadi lebih produktif, memiliki semangat yang besar, dan kemampuan menyelesaikan pekerjaan lebih dari biasanya. Stres ringan biasanya muncul dari kegiatan-kegiatan sehari-hari dan datang secara teratur biasanya berlangsung beberapa menit atau jam. Stres ringan juga dapat berguna dan memacu seseorang untuk berpikir dan berusaha lebih cepat dan keras sehingga dapat menghadapai tantangan hidup sehari-hari.

Hasil penelitian ini menemukan sebanyak 20 penyandang DM $(17,9 \%)$ mengalami stres berat. Stres berat merupakan situasi kronis yang dapat terjadi dalam beberapa minggu, seperti penyakit fisik jangka panjang dan kesulitan finansial. Stressor ini dapat menimbulkan gejala yaitu, merasa tidak kuat lagi untuk melakukan kegiatan, mudah putus asa, kehilangan minat akan segala hal, merasa tidak dihargai, merasa tidak ada hal yang bisa diharapkan di masa depan. Hasil penelitian Hermawan menunjukkan bahwa sebagian besar mengalami stres berat karena penyandang DM belum bisa menerima keadaan dirinya yang terkena DM dan belum terbiasa dengan pola hidup makan berpantang dan belum mampu menangani faktor penyebab stres dengan baik (Hermawan \& Purwanti, 2017). Dalam penelitian Azizah dan Hartanti menyatakan setiap individu memiliki penanganan stres yang berbeda. Apabila stres tersebut tidak diatasi dengan tepat, permasalahan yang harus dihadapi akan menimbulkan akibat gangguan sistem, timbulnya penyakit dan manifestasi klinis (Azizah \& Rita Dwi Hartanti, 2016).

Hasil penelitian ini juga mendapatkan 6 penyandang DM $(5,4 \%)$ mengalami stres sangat berat. Stres sangat berat merupakan situasi kronis yang dapat terjadi dalam beberapa bulan dan dalam kurun waktu yang tidak dapat ditentukan. Biasanya seseorang untuk hidup cenderung pasrah dan tidak memiliki motivasi untuk hidup. Seseorang dalam tingkatan stres ini biasanya 
teridentifikasi mengalami depresi berat ke depannya. Hasil pengambilan data penyandang DM dalam kategori stres sangat berat sangat sering marah-marah karena hal sepele, sangat sering mengalami kesulitan untuk bersantai, sangat sering menjadi orang yang tidak sabar, sangat sering merasa kesal, dan sering gelisah. Selain itu, penelitian ini juga menemukan penyandang DM yang tidak mengalami stres yaitu sebanyak 16 penyandang DM (14,3\%). Hal ini dikarenakan bahwa penyandang DM tersebut telah mampu manajemen diri dan telah mampu melakukan koping efektif untuk mengatasi stresnya. Hal itu sesuai dengan pendapat beberapa penyandang DM yang tidak mengalami stres yaitu berusaha membuat diri senang dengan tidak banyak berpikir, ikhlas menjadi penyakit yang dialami, dan selalu rutin melakukan kontrol gula darah ke pelayanan kesehatan.

Tingkat stres yang dialami penyandang DM satu dengan lain berbeda-beda, dipengaruhi beberapa faktor yaitu faktor biologis dapat berupa kondisi tubuh, dan faktor hereditor. Berbagai faktor tersebut diasosiasikan dengan stres psikologis, dampak terhadap perilaku, maupun kualitas hidup penyandang DM (Co et al., 2015). Selain itu, faktor sosio kultural dapat berupa perkembangan kepribadian dan pengalaman masa lalu. Sedangkan faktor lingkungan berupa lingkungan fisik, lingkungan biotik, dan lingkungan sosial. Dengan demikian, pengkajian stress pada penyandang DM pada dasarnya diperlukan sepanjang proses penyakit, tidak hanya pada saat terdiagnosis saja (Rariden, 2019).

Perbedaan tingkat stres yang dialami penyandang DM dipengaruhi oleh beberapa faktor yaitu faktor biologis dapat berupa kondisi tubuh, faktor sosio kultural dapat berupa perkembangan kepribadian, pengalaman masa lalu, dan faktor lingkungan berupa lingkungan fisik, lingkungan biotik, dan lingkungan sosial. Pada penelitian ini stres penyandang DM juga dipengaruhi oleh karakteristik demografi responden seperti jenis kelamin, usia, tingkat pendidikan, dan tingkat pekerjaan. Pada penelitian ini responden terbanyak adalah yang berjenis kelamin perempuan, usia penyandang DM dalam kategori dewasa tengah, tidak pernah sekolah, dan tidak memiliki pekerjaan. Hal tersebut dapat memicu stres pada penyandang DM (Zainuddin et al., 2015). Stres ringan, stres sedang, stres berat, dan stres sangat berat sama-sama perlu dilakukan pemantauan karena dapat berakibat pada gangguan pengontrolan glukosa. Semakin tinggi tingkat stres yang dialami penyandang DM, maka semakin tinggi pula kenaikan kadar gula darahnya. (Derek et al., 2017).

Munculnya gejala stres yang diakibatkan oleh kadar glukosa yang tidak terkontrol ini dapat mengganggu aktivitas individu seharihari dan menurunkan fungsi individu secara keseluruhan baik fungsi fisik, psikologis dan perilaku (Co et al., 2015). Berdasarkan hasil penelitian pada penyandang DM dari stres fisik penyandang DM menunjukkan bahwa sering merasa telah menghabiskan banyak energi untuk merasa cemas. Seseorang dengan diabetes akan merasa energinya berkurang sehingga mudah lelah dalam melakukan aktivitas sehari-hari. Kelelahan yang terjadi pada penderita penyakit kronis berlangsung secara terus-menerus, tidak hilang dengan istirahat sesaat, dan menyebabkan aktivitas fisik serta peran dan tanggung jawabnya menjadi berkurang. Stres emosional yang dialami oleh penyandang DM disebabkan oleh keadaan hidupnya yang terganggu dan tertekan karena mengidap penyakit yang tidak bisa disembuhkan (Siregar \& Hidajat, 2017).

Hasil penelitian menunjukkan stres emosional penyandang DM didapatkan beberapa gejala seperti, sering marah karena hal sepele, sangat sering bereaksi berlebihan, sering merasa kesal, sering mudah tersinggung, sering mudah marah, sering kesulitan untuk tenang setelah merasa kesal, sering kesulitan untu bersabar dalam menghadapi gangguan, dan sedang merasa gelisah. Sejalan dengan penelitian sebelumnya yang mengatakan bahwa stres yang disertai oleh sikap-sikap emosional lainnya berdampak pada dipatuhi atau tidak dipatuhinya penatalaksanaan pengobatan diabetes oleh penderita diabetes yang mengakibatkan peningkatan glukosa darah (Septian Adi Nugroho \& Purwanti, 2013). Stres perilaku menunjukkan bahwa setengah responden sulit untuk bersantai, sering tidak sabar, sering mengalami kesulitan 
beristirahat, dan sering tidak dapat memaklumi hal yang menghalangi untuk menyelesaikan masalah.

\section{SIMPULAN}

Hasil penelitian menyimpulkan bahwa sebagian besar penyandang DM mengalami stres sedang.

\section{DAFTAR PUSTAKA}

Azizah, R., \& Rita Dwi Hartanti. (2016). Hubungan antara Tingkat Stres dengan Hipertensi di Wilayah Kerja Puskesmas Wonopringgo Pekalongan. The 4th Universyty Reseach Coloquium, 261-278.

Bruce, 2011. (2013). Hubungan Koping terhadap Tingkat Stres dengan Pasien Diabetes Melitus di Poli Penyakit Dalam RSUD Raden Mattaher Jambi Tahun 2018. Journal of Chemical Information and Modeling, 53(9), 1689-1699.

https://doi.org/10.1017/CBO97811074 15324.004

Co, M. A., Tan, L. S. M., Tai, E. S., Griva, K., Amir, M., Chong, K. J., ... Wee, H.-L. (2015). Factors Associated with Psychological Distress, Behavioral Impact and Health-related Quality of Life among Patients with Type 2 Diabetes Mellitus. Journal of Diabetes and Its Complications, 29(3), 378-383. https://doi.org/10.1016/J.JDIACOMP. 2015.01.009

Derek, M., Rottie, J., \& Kallo, V. (2017). Hubungan Tingkat Stres dengan Kadar Gula Darah pada Pasien Diabetes Melitus Tipe II di Rumah Sakit Pancaran Kasih GMIM Manado. Jurnal Keperawatan, 5(1), 1-6.

Hermanns, N., Kulzer, B., Ehrmann, D., Bergis-Jurgan, N., \& Haak, T. (2013). The effect of a Diabetes Education Programme (PRIMAS) for People with Type 1 Diabetes: Results of a Randomized Trial. Diabetes Research and Clinical Practice. https://doi.org/10.1016/j.diabres.2013. 10.009
Hermawan, B., \& Purwanti, O. S. (2017). Hubungan antara Tingkat Stres dengan Kualitas Hidup Penderita Diabetes Melitus di Wilayah Kerja Puskesmas Gajahan Surakarta (Universitas Muhammadiyah Surakarta). Retrieved from http://eprints.ums.ac.id/52284/

Kelly, S. J., \& Ismail, M. (2015). Stress and Type 2 Diabetes: A Review of How Stress Contributes to the Development of Type 2 Diabetes. Annual Review of Public Health, 36(1), 441-462. https://doi.org/10.1146/annurevpublhealth-031914-122921

Lloyd, C., Smith, J., \& Weinger, K. (2005). Stress and Diabetes: A Review of the Links. Diabetes Spectrum, 18(2), 121 LP https://doi.org/10.2337/diaspect.18.2.1 21

Lutfi Wahyuni. (2015). Hubungan Stress dengan Kenaikan Kadar Gula Darah pada Penderita Diabetes Melitus di Ruang Dhoho RSUD Prof Dr Soekardar Mojosari. Jurnal Keperawatan Sehat, 11(1). Retrieved from http://ejournal.stikesppni.ac.id/index.php/JKS/article/view/ $143 / 0$

Perkumpulan Endokrinologi Indonesia (Perkeni). (2015). Konsensus Pengelolaan Dan Pencegahan Diabetes Mellitus Tipe 2 Di Indonesia 2015.

Pratiwi, P., Amatiria, G., \& Yamin, M. (2014). Pengaruh Stress terhadap Kadar Gula Darah Sewaktu pada Pasien Diabetes Melitus. Jurnal Kesehatan, v(1), 11-16.

Rariden, C. (2019). Diabetes Distress: Assessment and Management of The Emotional Aspect of Diabetes Mellitus. The Journal for Nurse Practitioners, 15(9), 653-656. https://doi.org/10.1016/J.NURPRA.20 19.06.020

Renabir, S., \& Reetu, K. (2011). Stress and Hormones. Indian $J$ Endocrinol Metab, 15(1), 18-22. 
Septian Adi Nugroho, \& Purwanti, O. S. (2013). Hubungan antara Tingkat Stres dengan Kadar Gula Darah pada Pasien Diabetes Melitus di Wilayah Kerja Puskesmas Sukoharjo I Kabupaten Sukoharjo, 43-51. Retrieved from http://journals.ums.ac.id/index.php/BI K/article/view/3768/2435

Setyorini, A. (2017). Stres dan Koping pada Pasien Dengan DM Tipe 2 dalam Pelaksanaan Manajemen Diet di Wilayah Puskesmas Banguntapan II Kabupaten Bantul. Health Sciences and Pharmacy Journal, 1(1), 1. https://doi.org/10.32504/hspj.v1i1.3

Siregar, L. B., \& Hidajat, L. L. (2017). Faktor yang Berperan terhadap Depresi, Kecemasan Kasus Puskesmas Kecamatan Gambir Jakarta Pusat. Jurnal Ilmiah Psikologi MANASA, 6(1), 15-22.

Strandberg, R. B., Graue, M., WentzelLarsen, T., Peyrot, M., \& Rokne, B. (2014). Relationships of DiabetesSpecific Emotional Distress, Depression, Anxiety, and Overall Well-being with HbA1c in Adult Persons with Type 1 Diabetes. Journal of Psychosomatic Research, 77(3), 174-179.

https://doi.org/10.1016/j.jpsychores.20 14.06.015

Utami, A. P., Jamaluddin, \& Khsanah, U. (2016). Gambaran Mekanisme Koping Stres pada Pasien Diabetes Mellitus di Wilayah Kerja Puskesmas Sambit Ponorogo Jawa Timur. UIN Syarif Hidayatullah Jakarta). Retrieved from http://repository.uinjkt.ac.id/dspace/ha ndle/123456789/37361

Utamie Puji Lestari, C., Kanbara, S., Setyawan, A., \& Taniguchi, H. (2008). Comparison of Social Support, Self Efficacy and Psychological Stress Response between Diabetes Type 2 Patients in Jogjakarta, Indonesia and Kobe, Japan. Diabetes Research and Clinical Practice, 79, Supple(0), S124. https://doi.org/http://dx.doi.org/10.101 6/S0168-8227(08)70958-6
Yan, L. S., Marisdayana, R., \& Irma, R. (2017). Hubungan Penerimaan Diri dan Tingkat Stres pada Penderita Diabetes Mellitus. Jurnal Endurance, 2(3),

312. https://doi.org/10.22216/jen.v2i3.2234

Zainuddin, M., Utomo, W., \& Herlina. (2015). Hubungan Stres dengan Kualitas Hidup Penderita Diabetes Mellitus Tipe 2. Jurnal Online Mahasiswa Program Studi Ilmu Keperawatan Universitas Riau, 2(1), 890-898. Retrieved from https://www.neliti.com/publications/18 8387/hubungan-stres-dengan-kualitashidup-penderita-diabetes-mellitus-tipe2

Zhou, H., Zhu, J., Liu, L., Li, F., Fish, A. F., Chen, T., \& Lou, Q. (2017). DiabetesRelated Distress and Its Associated Factors among Patients with Type 2 Diabetes Mellitus in China. Psychiatry Research, 252, 45-50. https://doi.org/10.1016/J.PSYCHRES. 2017.02.049 
Jurnal Ilmu Keperawatan Jiwa Volume 3 No 1, Hal 1 - 8, Februari 2020

Persatuan Perawat Nasional Indonesia Jawa Tengah 